\title{
Learning from your neighbor: tax-benefit systems swaps in Latin America
}

\author{
Olivier Bargain ${ }^{1,2}$ - H. Xavier Jara ${ }^{3}$ David Rodriguez ${ }^{3}$
}

Published online: 21 December 2017

(C) The Author(s) 2017. This article is an open access publication

\begin{abstract}
Over the last decades, Latin American countries have experienced a noticeable decrease in income inequality. While this trend is mainly associated with a decline in wage inequality, progressive reforms of the tax-benefit systems of the region may have played a role. While redistributive systems in Latin America are still in their infancy, they are constantly expanding and do so at different pace in the region. To investigate this point in a comparative way, the present study exploits newly developed tax-benefit microsimulation models for Ecuador and Colombia. These two neighboring countries show contrasted situations in terms of income distribution and we characterize the extent to which this difference is explained by different tax-benefit systems. The comparative nature of our microsimulation models allows us to swap tax-benefit systems between countries to produce counterfactual simulations whereby the system of a country is applied to the population of the other. In this way, we can decompose the total country difference in income distribution to extract the role of different tax-benefit policies. We confirm that the Ecuadorean system is more redistributive and quantify the difference: if the Ecuadorean system was applied to the Colombian population, the Gini coefficient would be reduced by 1.7 points in Colombia.
\end{abstract}

Electronic supplementary material The online version of this article

(https://doi.org/10.1007/s10888-017-9367-5) contains supplementary material, which is available to authorized users.

H. Xavier Jara

hxjara@essex.ac.uk

Olivier Bargain

olivier.bargain@u-bordeaux.fr

David Rodriguez

david.rodriguez@essex.ac.uk

1 Université de Bordeaux, Bordeaux, France

2 Institut Universitaire de France, Paris, France

3 Institute for Social and Economic Research (ISER), University of Essex,

Wivenhoe Park, Colchester, Essex, CO4 3SQ, UK 
Headcount poverty would decrease by around $10 \%$ and the intensity of poverty by up to $14.7 \%$. This analysis contributes to the recent literature on the redistributive role of taxbenefit systems in Latin America and highlights the role of microsimulation techniques to show how countries in the region can learn from each other in order to improve social protection and reduce income inequality.

Keywords Tax-benefit policy $\cdot$ Microsimulation $\cdot$ Inequality $\cdot$ Poverty

\section{Introduction}

During the last decade, Latin America has experienced an important decrease in household income inequality (Lustig et al. 2013; Alvaredo and Gasparini 2015). Recent studies have shown that the main driver must have been the reduction in wage inequality (Abad and Lindert 2017; De la Torre et al. 2017). But, changes in tax-benefit systems, in the form of more progressive income taxation and higher cash transfers to vulnerable populations, have also played a role. According to Cord et al. (2014), around one-third of changes in income inequality in Latin America in the 2000s can be attributed to the development of redistributive systems. Despite these improvements, income inequality remains high in the region and redistributive systems in Latin America are still in their infancy. Taxes represent about $23 \%$ of GDP, compared to $34.3 \%$ in the OECD, and indirect taxes still play a major role while progressive taxation is modest. Public pensions spending in Latin America is half the size of the OECD, and direct transfers to the working age population (conditional cash transfers in Latin America) represent only $0.4 \%$ of GDP compared to $4.2 \%$ in the OECD. ${ }^{1}$

The role played by the tax-benefit system varies widely across countries. The present study provides a case study over two neighboring countries, Ecuador and Colombia, which show very different profiles of income distribution. ${ }^{2}$ Ecuador is an interesting example of one of the countries in the region that has achieved a large decrease in income inequality and poverty over the recent years, partly thanks to the development of generous transfers to the poorest part of the population. While having a similar economy, ${ }^{3}$ Colombia has experienced a much smaller decrease in income inequality over time and developed a more modest redistributive system. To put things in perspective, note that on average, tax-benefit systems in Latin America decrease the Gini coefficient from 50.8 (market income) to 48.1 (disposable income), according to Lustig (2017) for the year $2011 .^{4}$ The two countries under study present sharp contrasts around this regional average. According to our calculations for the year 2014, Ecuador starts with lower inequality levels and provides more redistribution,

\footnotetext{
${ }^{1}$ Social spending remains below $15 \%$ of GDP, compared to more than $25 \%$ on average in OECD countries.

${ }^{2}$ The vast majority of distributional analyses in Latin America are based on household income rather than consumption. This is due to the fact that most Latin American countries collect income information on a regular basis in household surveys, whereas consumption data is collected only over long periods of time. The concept of analysis is often market income augmented with cash transfers, i.e. information on tax and social insurance contribution is not always available in the data. Microsimulation studies remedy partly to this by simulating a broader concept of disposable income.

${ }^{3}$ Ecuador and Colombia are middle ranked countries in terms of GDP per capita. Both countries heavily depend on primary resources revenue, in particular oil which represented around 50\% of exports in 2014 in both countries.

${ }^{4}$ In comparison, the Gini coefficient for the EU28 falls from 50.1 to $29.2 \%$ on average, when market income is compared to disposable income (See EUROMOD statistics on Distribution and Decomposition of Disposable Income, accessed at http://www.euromod.ac.uk/using-euromod/statistics).
} 
with a Gini falling from 50.1 to $46.2 \%$. Colombia shows the opposite situation, with a Gini falling from 59.2 to $56.4 \%$.

Proper characterizations and comparisons of the redistributive potential of these countries require tools like microsimulation models that allow a comparative perspective. More generally, the importance of building tax-benefit microsimulation models for developing countries was highlighted by Atkinson and Bourguignon (1990), as such models should "lead to a comprehensive, powerful and yet simple instrument for the design of an efficient redistribution system adapted to the specificity of developing countries". 5 The need of developing accessible and comparable tax-benefit models was also pointed out, ${ }^{6}$ even though cases of such comparative settings still remain rare. The pioneering work by Atkinson et al. (1988), which used national tax-benefit models to compare policy effects in France and the UK, inspired the development of the European microsimulation model EUROMOD, which is probably the only example of a harmonized model allowing proper international comparisons.

The present paper takes advantage of the recent development of such harmonized microsimulation models for Ecuador and Colombia, ECUAMOD and COLMOD. On this basis, we provide one of the first comparative microsimulation studies for Latin American countries. These microsimulation models are based on rich representative household microdata for each country. They are developed as a multi-country microsimulation embedded in the modeling structure of EUROMOD. This means that every redistributive instrument is defined according to the same core calculation and definition, using similar data treatment for source income and household characteristics, hence guaranteeing a harmonized framework for international comparisons (see Sutherland and Figari 2013). ${ }^{7}$ Armed with this tool, we assess the distributional effects of the Ecuadorean and Colombian tax-benefit systems by "swapping" tax-benefit rules between the two countries. This approach consists in simulating a series of counterfactual scenarios whereby the tax-benefit rules of one country are applied to the population of the other country. These counterfactual simulations are components of a decomposition that allows disentangling and quantifying the impact of national policy rules on income distribution.

Several microsimulation exercises in the literature have consisted in swapping particular policies from one country to another when using the European microsimulation model EUROMOD, learning from how the effects of policies differ across different populations and economic circumstances. Examples of this kind of "policy learning" experiments include swap simulations of unemployment benefit schemes in Belgium and the Netherlands (De Lathouwer 1996) or of child and family benefits in France and the UK (Atkinson et al. 1988), Austria, Spain and the UK (Levy et al. 2007b) or Baltic and Eastern European

\footnotetext{
${ }^{5}$ Focusing on Brazil as a case study, they found that much of the redistribution in the existing Brazilian system in the 1980's relied on instruments that were less important in OECD countries. For example, indirect taxes, subsidies and the provision of targeted non-cash benefits such as public education and subsidized school meals were found to be more important. Instruments more important in OECD systems and often the main instruments in tax-benefit models (personal income taxes, social insurance contributions and pensions), were largely confined to the modern sector in Brazil and thus of less importance to policy makers. Nevertheless they argued that sufficient data existed at the time to simulate many of the Brazilian specific instruments in addition to the "classic" ones.

6 These recommendations have materialized in the production of national tax-benefit models for a few Latin American countries, such as Brazil, Chile, Guatemala, Mexico and Uruguay (Immervoll et al. 2009; LópezCalva and Urzúa 2011; Urzúa 2012). However, such national models do not necessarily provide a harmonized setting for cross-country comparative analysis.

${ }^{7}$ It is also the basis for a more generalized comparative tool for many more countries of the region, to be developed in the next years.
} 
countries (Salanauskaite and Verbist 2013). The present study is the first to perform a swap of the whole tax-benefit systems between two countries. In this way, it completes the suggestion of Atkinson et al. (1988) that led to the development of EUROMOD. The decomposition method used in this paper to isolate the redistributive role of tax-benefit systems is inspired from earlier contributions (Bargain and Callan 2010; Bargain 2012). However, instead of comparing the same country over two different periods in time, as in the latter, we originally compare two different countries for the same policy year (see the discussion of the general decomposition framework in Bargain 2012).

Our results confirm the small redistributive role of tax-benefit systems in Ecuador and Colombia, based on policy rules of 2014. As expected, the Ecuadorean system achieves a larger degree of redistribution than the Colombian system. Under the counterfactual scenarios where the Colombian (Ecuadorean) tax-benefit system is applied to the Ecuadorean (Colombian) population, the Gini coefficient in Ecuador (Colombia) would increase (decrease) by 1.9 (1.7) points. Our decomposition shows that differences in taxbenefit rules between Ecuador and Colombia account for 1.8 points of the total difference in inequality, on average. Results are even more impressive in terms of income poverty. If Colombia adopted the Ecuadorean system, headcount poverty would decline by around $10 \%$ (3.4 points) while the intensity of poverty would be reduced by $14.7 \%$. The effect is largest for the elderly population in Colombia as headcount elderly poverty would fall by $18.7 \%$. This result relates to the more generous social assistance benefit in place in Ecuador, which targets the elderly not covered by contributory pensions.

The remainder of this paper is structured as follows. Section 2 presents statistics on tax-benefit systems in Latin America and the countries under studies. It also summarizes previous research on the redistributive effect of tax-benefit systems in Latin America. Section 3 describes the data, the microsimulation models and presents the decomposition approach used in the analysis. Section 4 shows and discusses the results of our tax-benefit swapping exercise. Section 5 concludes.

\section{Tax-benefit systems and income redistribution in Latin America}

This section provides a general overview of the characteristics of tax-benefit systems in Latin America and their redistributive role, relative to developed economies. We start by discussing how the size and composition of tax-benefit systems in Latin America compares to those of OECD countries, and put into perspective the situation of Ecuador and Colombia. We then summarize the recent literature on the redistributive effect of tax-benefit systems in Latin America, with a particular focus on these countries.

\subsection{Statistics in a comparative perspective}

Latin America Relative to OECD countries, the size of the tax-benefit system remains modest in Latin America, despite important improvements over the last decades. In terms of taxes, the average tax-to-GDP ratio in Latin America and the Caribbean (LAC) increased from $15.8 \%$ in 1990 to $22.8 \%$ in 2015 but it is still below the OECD average of $34.3 \%$ (OECD/ECLAC/CIAT/IDB 2017). LAC countries are also characterized by a different tax composition relative to developed economies. Mainly due to their ease of collection, indirect taxes on goods and services remain very important, representing $49.1 \%$ of tax revenues in LAC countries, broken down in $28.4 \%$ for VAT (compared to around $20 \%$ in the OECD) and $20.7 \%$ for other indirect taxes. Other tax revenues in LAC countries came from the 
combination of taxes on income and profits (27.2\%) and social security contributions (16.4\%) in 2015, compared to $33.7 \%$ and $26.2 \%$ respectively in the OECD. Out of all taxes, the share of personal income tax in LAC countries is low compared to OECD economies. In 2014 , it represented $34.1 \%$ (against $65.9 \%$ for corporate income tax) of total income tax revenue, compared to $73.2 \%$ (against $26.8 \%$ ) in the OECD.

In terms of benefits, social spending has also increased, from $11.3 \%$ of GDP in 1990 to around $14 \%$ in 2014 , but remains low compared to $21.1 \%$ in the OECD (cf. CEPAL 2004, OECD 2017). Nonetheless, non-contributory transfers are nowadays smaller but of a similar magnitude as in richer countries. For instance, while public pensions represent $4.5 \%$ of GDP in the LAC region compared to $8.2 \%$ in the OECD (Bernal 2016), non-contributory pensions amount to an average of $0.45 \%$, which is similar to that of a country like Spain (the OECD average is $1.55 \%$ ). Direct cash transfers to vulnerable population subgroups in Latin America are mainly made of conditional cash transfers and represent around $0.4 \%$ of GDP (CEPAL-IEF 2014), which is similar in size to the $0.5 \%$ of GDP expenditures in social exclusion benefits in the EU-27 but below the transfers in some countries (for instance, France spends $0.8 \%$ of GDP on welfare payment to working and idle poor). ${ }^{8}$

The modest size of tax-benefit systems in Latin American countries is reflected in their small redistributive role. On average tax-benefit systems in Latin America reduce income inequality, measured by the Gini coefficient, by 2.7 points (from 50.8 to 48.1 ) when market income is compared to disposable income in 2011 (Lustig 2017). The effect is particularly small compared to European economies, where the tax-benefit system reduces income inequality by around 20.9 points on average (from 50.1 to 29.2 ) ${ }^{9}$ One of the main issues is the lack of targeting of non-contributory benefits, only half of it reaching the poor on average (Robles et al. 2015).

Ecuador Ecuador is an interesting example of a country that has achieved a large decrease in income inequality and poverty. According to data from the Socio-Economic Database for Latin America and the Caribbean (SEDLAC), the Gini coefficient of household income per capita in Ecuador fell from 53.6\% in 2004 to $45.2 \%$ in $2014 .{ }^{10}$ Over the same period, Ecuador also experienced an important decrease in poverty, with the absolute poverty headcount falling from $48.0 \%$ in 2004 to $23.6 \%$ in $2014 .^{11}$

\footnotetext{
${ }^{8}$ Other types of benefits represent a larger share of direct transfers for the working-age population in the EU: family benefits ( $2.4 \%$ of GDP), unemployment benefits ( $1.4 \%$ of GDP), housing benefits ( $0.6 \%$ of GDP). See Eurostat social protection statistics: http://appsso.eurostat.ec.europa.eu/nui/show.do?dataset=spr_exp_sum\& lang=en

${ }^{9}$ See EUROMOD statistics on Distribution and Decomposition of Disposable Income, accessed at http:// www.euromod.ac.uk/using-euromod/statistics

${ }^{10}$ Note that differences between SEDLAC figures and our results are on account of the use of different surveys in the analysis. SEDLAC statistics for Ecuador are based on the National Survey of Employment, Underemployment and Unemployment (Encuesta Nacional de Empleo, Desempleo y Subempleo). Statistics for Colombia are based on the Integrated Household Survey (Gran Encuesta Integrada de Hogares). Moreover, SELDAC figures are based on the concept of market income augmented with cash transfers, i.e. taxes and social insurance contributions are not deducted as in general no information is available in household surveys. For more information see: http://sedlac.econo.unlp.edu.ar/eng/index.php.

${ }^{11}$ SEDLAC figures on poverty as well as those extracted from Lustig (2017) are obtained using a poverty line of USD 4.00 PPP per day. Note that the 23.6\% figure for 2014 seems still overstated compared to our estimations (18\%). As explained later, the differences are driven by (i) different datasets (the data we use contains much more detailed income information than the yearly survey used by SEDLAC (see Jara et al. 2017, and confirmations by the national statistical institute), (ii) different income concepts (we use household disposable income while SEDLAC uses market income plus cash transfers, as explained in footnote 12).
} 
Tax revenue in Ecuador is similar in size to the region average, with a tax-to-GDP ratio of $21 \%$ in 2014. The composition of tax revenue differs slightly. Indirect taxes represented $40 \%$ of total tax revenue in 2014 (below the region average), income tax accounted for $23.1 \%$ (personal income tax representing only $24 \%$ against $76 \%$ for corporate income tax) and social insurance contributions accounted for $27.9 \% .^{12}$ In terms of benefits, non-contributory (contributory) pensions account for around 0.3\% (4\%) of GDP. Ecuador presents one of the highest levels of public spending in social assistance conditional cash transfers among Latin American countries, amounting to $0.5 \%$ of GDP in 2014. In-kind benefits are similar to the region average.

The tax-benefit system in Ecuador is more redistributive than average among LAC countries. According to our results the Gini coefficient decreases by 3.9 points (from 50.1 to 46.2) when market income is compared to disposable income in 2014 , whereas absolute poverty decreases by 3.6 points.

Colombia This country has experienced a much smaller decrease in income inequality over time than its neighbor, with the Gini coefficient of household income per capita falling from $56.0 \%$ in 2004 to $53.3 \%$ in 2014, according to SEDLAC. The decrease in poverty over time has been impressive, yet not as pronounced as in Ecuador, with the absolute poverty headcount falling from $49.4 \%$ in 2004 to $28.9 \%$ in 2014.

Tax revenue in Colombia is similar in size to Ecuador, with a tax-to-GDP ratio of $20.8 \%$. Indirect taxes represented $35.4 \%$ of total tax revenue in 2014, while social insurance contributions accounted for $29.54 \%$. Income tax is relatively larger in size for the region, accounting for $32.28 \%$ of tax revenue in 2014 . However, out of total income tax only $10 \%$ corresponded to personal income tax with corporate tax accounting for a large $90 \%$ (DANE 2017a). In terms of benefits, only $0.1 \%$ of GDP is allocated to the non-contributory pension program Colombia Mayor (while contributory pensions account for around 5\% of GDP in 2014). Public spending in social assistance transfers (including non-contributory pensions) represented $0.3 \%$ of GDP. ${ }^{13}$

According to our results, the redistributive role of the tax-benefit system in Colombia is smaller compared to Ecuador, with the Gini coefficient falling by 2.8 points (from 59.2 to 56.4) when market income is compared to disposable, and absolute poverty falling by 3.5 points. Note that this characterization, as much as our own calculations in what follows, focuses on cash transfer while in-kind benefits are beyond its scope. ${ }^{14}$

\subsection{Related literature}

Despite the little progressivity characterizing tax-benefit systems in Latin America, their redistributive role has grown over the past two decades, notably with the introduction of conditional cash transfers targeting low income families (Abad and Lindert 2017;

\footnotetext{
12 Revenue statistics are available from the Internal Revenues Service (Servicio de Rentas Internas) at: http://www.sri.gob.ec/web/guest/estadisticas-generales-de-recaudacion regarding taxes, from IESS (2014) regarding social insurance contributions, from Jara et al. (2017) regarding personal income tax.

${ }^{13}$ Figures are based on a report of the Ministry of Labor to the Colombian Congress, available at: www.mintrabajo.gov.co/documents/20147/266052/Informe+al+Congreso+de+actividades+del+Sector+Trabajo+20142015.pdf; and management report of the Department of Social Prosperity, available at: http://www.prosperidadsocial.gov.co/ent/gen/trs/Documents/Informe\%20Gesti\%C3\%B3n\%20DPS\%20-\%202014.pdf

${ }^{14}$ Public expenditure in education (health) represents $4.6 \%$ (4\%) of GDP in LAC compared to 5.3\% (6.2\%) in the OECD (cf. OECD 2017). Ecuador is close to the average with 4.7\% (4\%) in 2014 (cf data from the General State Budget, available at: http://www.finanzas.gob.ec/ejecucion-presupuestaria/). So is Colombia, with $4.6 \%$ (4.9\%) in 2014 (DANE 2017b).
} 
De la Torre et al. 2017). According to Cord et al. (2014), around one-third of changes in income inequality in Latin America in the 2000s can be attributed to the redistributive role of tax-benefit systems. Back in the early 2000s, tax-benefit systems in Latin America operated only a very small redistributive effect, as shown by Goñi et al. (2011) using World Bank's World Development Indicators (WDI) enhanced with information about the incidence of taxes and transfers from other studies. They show that on average direct taxes and cash transfers in European countries decrease Gini by around 15 points (from 46.0 to 31.0) versus only 2 points only (from 52.0 to 50.0) on average in Argentina, Brazil, Chile, Colombia, Mexico and Peru. They highlight a minor role of tax, which is attributed to low tax collection due to evasion as well as high exemptions and deductions; in case in-kind benefits are considered, Latin American tax-benefit systems achieve a larger redistribution (5 point decrease in Gini), but still much less than in European countries (21 point decrease). The results are in line with findings by Barreix et al. (2006), who use household survey data from the early 2000s for Colombia, Bolivia, Ecuador, Peru and Venezuela.

For the more recent period, CEPAL-IEF (2014) study 17 Latin American countries using household surveys from 2012 with imputed information for direct taxes and in-kind benefits. Compared to the early 2000s, most Latin American countries experienced a decrease in income inequality and the role of the tax-benefit system also increased, with a Gini reduction of 9 points on average (from 51.0 to 42.0) including 6 points solely due to inkind benefits. Colombia is among the countries achieving the least redistribution (especially when in-kind benefits are not considered) whereas Ecuador is close to the region average. The Commitment to Equity (CEQ) Institute has also suggested a common imputation methodology for most Latin American countries around the year 2010, with the aim of studying the incidence of taxes and benefits. The main difference between the imputation approach and microsimulation techniques is that the latter systematically apply legislation rules for the simulation of tax-benefit instruments - and hence allows simulating counterfactual systems as in our 'policy swaps' - provided that information for the simulations is available in the data (for instance, earnings, capital income, relevant demographics, etc.). The imputation approach directly uses the information on taxes and transfers available from the data while it imputes the rest from other sources. ${ }^{15}$ Using this approach, Lustig (2017) confirms the best performances of country like Argentina, Uruguay and Brazil while Colombia is among the countries redistributing the least. Ecuador ranks 5th (out 16 countries) in terms of redistributive effect of the tax-benefit system. The results further highlight that countries with similar levels of market income inequality (for instance Brazil, Honduras and Colombia) achieve different levels of redistribution. In terms of income poverty, direct taxes and benefits reduce extreme poverty in 12 out of the 16 countries analyzed, however to very different extents. The effect of tax-benefits policies on poverty reduction is about twice larger in Ecuador than in Colombia.

Finally, only few microsimulation studies exist for Latin America. Tax-benefit microsimulation models were developed for Brazil, Chile, Guatemala, Mexico and Uruguay and used in López-Calva and Urzúa (2011) based on household survey data for 2008-2009. Urzúa (2012) compiles a number of national studies making use of the models, but does not provide a comparative analysis of the redistributive effect of tax-benefit systems across countries. Despite the advantages offered by microsimulation techniques to assess the redistributive effect

\footnotetext{
${ }^{15}$ In Ecuador, the survey data used for the analysis, Encuesta Nacional de Ingresos y Gatos Urbanos y Rurales, ENIGHUR 2011-2012, records information on direct taxes and social insurance contributions, so these are taken directly from the data (Llellena et al. 2015).
} 
of tax-benefit systems, very little use has been given to such models for cross-country comparative analysis in Latin America. One possible reason for this might be an underlying lack of comparability in the implementation of policy simulations across national tax-benefit models.

\section{Methodology}

We start this section by presenting the data used and the microsimulation models. We describe the tax-benefit policies covered by our models and discuss how our simulations compare to external statistics in terms of the number of recipients and payers as well as of aggregate annual amounts of simulated benefits and taxes. Then, we provide a detailed description of the decomposition approach used to evaluate the effect of swapping tax-benefit systems between Ecuador and Colombia.

\subsection{Data and simulations}

Data Our results are based on representative household survey data from Ecuador and Colombia. Data from Ecuador comes from the National Survey of Income and Expenditures of Urban and Rural Households (Encuesta Nacional de Ingresos y Gastos de Hogares Urbanos y Rurales, ENIGHUR) 2011-2012. Data from Colombia comes from the Quality of Life National Survey for 2014 (Encuesta Nacional de Calidad de Vida, ENCV). Both surveys contain detailed information on household and personal characteristics, employment, earnings, income from capital and property, private transfers, income from remittances, cash transfers, pensions, and expenditures. Income concepts have been harmonized in both datasets with the aim to achieve comparability in the simulation results (see Jara et al. 2017 and Rodriguez 2017). The sample for our simulations contains 153,341 individuals for Ecuador and 67,332 individuals for Colombia.

Tax-benefit simulations Our study makes use of the newly developed tax-benefit microsimulation models ECUAMOD and COLMOD. ${ }^{16}$ ECUAMOD and COLMOD combine detailed country-specific coded policy rules with cross-sectional micro-data in order to simulate direct taxes and social insurance contributions, as well as cash transfers for the household population of Ecuador and Colombia. The models have been implemented on the EUROMOD software, which enables users to analyze the effect of tax-benefit policies on the income distribution in a comparable manner across countries. Both, ECUAMOD and COLMOD, are static models in the sense that tax-benefit simulations abstract from behavioral reactions of individuals and no adjustments are made for changes in the population composition over time.

Our analysis takes 2014 policies (as on June 30th) in Ecuador and Colombia as the starting point. In the case of Ecuador, market incomes and non-simulated tax-benefit variables in the 2011-12 data are adjusted to 2014 levels using source-specific updating factors (Jara et al. 2017). Table 1 provides a summary of the tax-benefit instruments simulated in ECUAMOD and COLMOD for the purpose of our exercise.

\footnotetext{
${ }^{16}$ ECUAMOD has been developed as part of UNU-WIDER's project on 'SOUTHMOD—simulating tax and benefit policies for development' in which tax-benefit microsimulation models have being built for selected developing countries. Simulation results for ECUAMOD have been validated both at the micro and macro level (see Jara et al. 2017). For more information about SOUTHMOD see: https://www.wider.unu. edu/project/southmod-simulating-tax-and-benefit-policies-development.
} 
Table 1 Tax-benefit instruments simulated in Ecuador and Colombia (2014)

\begin{tabular}{lll}
\hline Ecuador Colombia & Cor
\end{tabular}

Employee social insurance contributions

- All employees are liable to pay SICs

- Contribution base is gross employment income

- Total contribution rate is either 9.45 or $11.45 \%$ depending on the category of the worker

- No SICs are paid if income below 340 USD

Self-employed social insurance contributions

- Self-employed workers can contribute to SICs on a voluntary basis

- Contribution base is declared gross self-employment income

- Total contribution rate is $20.50 \%$

- No SICs are paid if income below 340 USD

Personal income tax

- Tax unit is the individual

- Taxable income is gross labor income plus extra pay plus utilities participation plus SICs

- Exemptions include income from pensions, 13th and 14th months, reserve funds, and deductions for old age and disability

- Deductions include SICs and deductions from personal expenditures in food, clothing, education, health, and housing

- Tax base is taxable income minus exemptions, minus deductions

- Tax schedule is formed of nine bands and rates from 0 and $35 \%$

Social Assistance benefits

\section{Human Development Transfer}

- Proxy means-tested benefit based on the composite index of the Social Registry

- Eligible are: (i) poor families with children below 18 years; (ii) vulnerable elderly not affiliated with social security, not receiving pensions; and (iii) vulnerable persons with $40 \%$ or higher degree of disability, not affiliated with social security

- Amount: 50 USD per month

- Conditionality for children: school enrolment and attendance, and medical check-ups
- All employees are liable to pay SICs

- Contribution base is gross employment income

- Total contribution rate is between 8 and $10 \%$ depending on employment income

- Min. contribution: $8 \%$ of a minimum wage. Max. contribution: $12 \%$ of 25 minimum wages

- All self-employed are liable to pay SICs

- Contribution base is $40 \%$ of gross self-employment income

- Total contribution rate is between 8 and $10 \%$ depending on income

- Min. contribution: $8 \%$ of a minimum wage. Max. contribution: $12 \%$ of 25 minimum wages

- Tax unit is the individual

- Taxable income is labor income, extra pay, pension income and income from assets

- Exemptions include income from company ownership, taxed as business tax; depending on the system up to $25 \%$ of labor income

- Deductions include expenditure in education, health and mortgage payments

- Tax base is taxable income minus exemptions, minus deductions

- Tax schedule is formed of different bands contingent on the system applied, rates are between 0 and $33 \%$

\section{Familias en acción}

- Proxy means-tested benefit based on a composite welfare index (SISBEN)

- Eligible are: families with children below 18

- Amount: (i) health component:

33-38 USD per month per family;

(ii) education component:

11-24 USD per month per child for up to 3 children

- Conditionality for children: school enrolment and attendance, and medical check-ups 
Table 1 (continued)

\begin{tabular}{lc}
\hline Ecuador & Colombia \\
\hline Joaquín Gallegos Lara Transfer & Colombia mayor \\
• Benefit for persons caring for individuals & $\bullet$ Proxy means-tested benefit based on a \\
with severe disability and/or illness & composite welfare index (SISBEN) \\
- Amount 240 USD per month & $\bullet$ Eligible are: elderly older aged 54 years (female) \\
& and 58 years (male) or more; no pension income \\
& - Amount: Between USD 21 and USD 59 per month \\
& depending on city/town
\end{tabular}

Notes: SIC - social insurance contributions; USD - US dollars. Exchange rate for 30th June 2014

Source: authors' compilation

In both countries, employee and self-employed social insurance contributions are simulated in our models. Some important differences in the design of SICs between Ecuador and Colombia can be highlighted. First, all self-employed workers are liable to pay SICs in Colombia, whereas payment is voluntary for this group in Ecuador. Second, the contribution base for the self-employed corresponds to the totality of self-employment income in Ecuador, whereas only $40 \%$ of it is considered in Colombia. Contribution rates in Ecuador vary depending on the sector of work, whereas they vary depending on income in Colombia. Finally, an important difference refers to the exemption of SIC payments for incomes below the minimum wage in Ecuador (USD 340 in 2014), whereas a minimum SIC payment equivalent to $8 \%$ of minimum wage is compulsory in Colombia. Note that both ENIGHUR 2011-2012 and ECV 2014 contain information about affiliation to social security for each individual in the data. Our models simulate SIC payments only for those individuals, who report affiliation to the social security system in the survey.

Income tax has become increasingly important as a source of government revenue in Ecuador and Colombia. The design of personal income tax varies between these countries but it also presents some interesting similarities. In particular, in both countries, personal income tax is characterized by the presence of deductions from personal expenditures in education, health, housing, and in the case of Ecuador also expenditures in food and clothing. The small redistributive role of income tax in Latin American countries is usually attributed to the presence of such deductions. Furthermore, the structure of personal income tax in Colombia is more complex than in Ecuador. In addition to the standard tax regime another two alternative regimes were introduced in 2012 in order to prevent the excessive use of deductions. ${ }^{17}$ In both, ECUAMOD and COLMOD, personal income tax is simulated under the assumption of full compliance. Simulation of some sort of tax evasion would necessarily require strong assumptions about who is evading tax. Assuming, for instance, that only individuals affiliated with social security pay income tax would underestimate income tax payment of the self-employed, who can opt for affiliation on a voluntary basis in Ecuador but who are still liable to pay income tax. Our results for income tax, therefore, represent the intended effect of the tax system. As we shall see, even under the assumption of full compliance, the redistributive effect of income tax in Ecuador and Colombia is small, as previously found in the literature.

\footnotetext{
${ }^{17}$ The alternative tax regimes were abolished in the tax reform of 2016, as they were deemed too complex. For a detailed description of the personal income tax rules in Colombia, see Rodriguez (2017).
} 
In terms of social assistance, our models simulate the main cash transfers available in Ecuador and Colombia. The Human Development Transfer (HDT) in Ecuador and Familias en acción in Colombia are proxy means-tested conditional cash transfers. These programs have an important impact on poverty alleviation as they are targeted to low income families. In Ecuador, the HDT represents $0.8 \%$ of GDP, whereas Familias en accion represents $0.3 \%$ of GDP. In both countries, the proxy means-test is based on composite welfare indices. The indices are based on a series of variables containing information on household characteristics, household head's characteristics, housing, living conditions, assets, and territory, among others. For both Ecuador and Colombia, we are able to replicate the composite indices for each household in the data in order to simulate eligibility for social assistance. ${ }^{18}$ In both countries, families with children ranking low according to the composite indices are eligible for social assistance, as long as the conditionality of school enrolment and medical check-ups is fulfilled. In Ecuador the HDT also targets old-age individuals, who are not affiliated with social security and not receiving pensions. In Colombia, the correspondent social benefit for the elderly is Colombia Mayor. Such schemes represent a type of non-contributory pension, aimed at protecting vulnerable elderly population not covered by social security, which we simulate as part of social assistance in our models. Finally, another population group eligible for HDT are persons with severe disabilities. Additionally, a disability carer benefit, the Joaquin Gallegos Lara transfer, is also part of social assistance in Ecuador and aims to improve living conditions of people with severe disability by providing a monthly payment to their carers.

Scope of the simulations Our analysis focuses on the concept of disposable income, that is, market income after income tax and SICs deductions and after receipt of cash benefits. Indirect taxes and in-kind benefits are not considered but the implications of including them in the analysis are discussed in our conclusions. ECUAMOD and COLMOD simulations cover the most important direct taxes and cash transfers present in Ecuador and Colombia. Table 2 provides a list of all income components used in our simulation models. Due to data limitations, some tax-benefit instruments cannot be simulated and are taken directly from the data. Therefore, the effect of these policies when applied to the other country in our counterfactuals cannot be assessed. This includes contributory public pensions and severance payments, which cannot be simulated given the lack of information on contribution records in the surveys, most disability benefits (which are then partially simulated) because of insufficient information on the degree of disability, and property taxes and motor vehicle taxes due to the absence of information about property and vehicles value in the data. In Ecuador, the housing grant cannot be simulated due to lack of information about the price of the property individuals intend to buy nor about the cost of planned remodeling for their current house; scholarships cannot be simulated because no information about students' grades to determine eligibility for scholarships is available in the data. In Colombia, displacement/emergency benefit cannot be simulated because of its contingent nature not captured in the survey. With the exception of contributory pensions, all other non-simulated instruments represent a minor part of tax-benefit systems in Ecuador and Colombia.

Validation Tables A1 and A2 in the Online appendix compare the number of recipients and payers, and aggregate annual amounts of simulated benefits and taxes obtained with

\footnotetext{
${ }^{18}$ We are grateful to the National Department of Planning (DNP) of Colombia for computing the SISBEN indices for our dataset.
} 
Table 2 Simulated and non-simulated income components in ECUAMOD and COLMOD

\begin{tabular}{|c|c|c|c|}
\hline Income component & $\begin{array}{l}\text { Treatment in } \\
\text { ECUAMOD }\end{array}$ & $\begin{array}{l}\text { Treatment in } \\
\text { COLMOD }\end{array}$ & Why not fully simulated? \\
\hline Market income & $\begin{array}{l}\text { Taken from } \\
\text { the data }\end{array}$ & $\begin{array}{l}\text { Taken from } \\
\text { the data }\end{array}$ & - \\
\hline \multicolumn{4}{|c|}{ Simulated tax-benefit instruments: } \\
\hline Employee SICs & Simulated & Simulated & - \\
\hline Self-employed SICs & Simulated & Simulated & - \\
\hline Personal income tax & Simulated & Simulated & - \\
\hline $\begin{array}{l}\text { Human development } \\
\text { transfer (HDT) }\end{array}$ & Simulated & - & - \\
\hline Joaquín Gallegos Lara & $\begin{array}{l}\text { Partially } \\
\text { simulated }\end{array}$ & - & $\begin{array}{l}\text { Eligibility for the benefit cannot } \\
\text { be simulated to lack of } \\
\text { information about severity of } \\
\text { disability in the data }\end{array}$ \\
\hline Familias en acción & - & Simulated & - \\
\hline Colombia Mayor & - & Simulated & - \\
\hline $\begin{array}{l}\text { Forced displacement and } \\
\text { humanitarian relief benefit }\end{array}$ & - & $\begin{array}{l}\text { Partially } \\
\text { simulated }\end{array}$ & $\begin{array}{l}\text { Eligibility for the benefit cannot } \\
\text { be simulated due to the } \\
\text { contingent nature of the benefit }\end{array}$ \\
\hline \multicolumn{4}{|c|}{ Non-simulated tax-benefit instruments: } \\
\hline $\begin{array}{l}\text { Contributory public pensions } \\
\text { and severance payments }\end{array}$ & $\begin{array}{l}\text { Taken from } \\
\text { the data }\end{array}$ & $\begin{array}{l}\text { Taken from } \\
\text { the data }\end{array}$ & No data on contribution records \\
\hline Scholarships & $\begin{array}{l}\text { Taken from } \\
\text { the data }\end{array}$ & - & $\begin{array}{l}\text { No information about students' } \\
\text { grades to determine eligibility } \\
\text { for scholarships }\end{array}$ \\
\hline Housing grant & $\begin{array}{l}\text { Taken from } \\
\text { the data }\end{array}$ & - & $\begin{array}{l}\text { No information about the price } \\
\text { of the property individuals } \\
\text { intend to buy nor about the } \\
\text { cost of planned remodeling } \\
\text { for their current house }\end{array}$ \\
\hline Property tax & $\begin{array}{l}\text { Taken from } \\
\text { the data }\end{array}$ & $\begin{array}{l}\text { Taken from } \\
\text { the data }\end{array}$ & $\begin{array}{l}\text { No information on property } \\
\text { values in the data }\end{array}$ \\
\hline Wealth tax & $\begin{array}{l}\text { Taken from } \\
\text { the data }\end{array}$ & - & $\begin{array}{l}\text { No detailed information on } \\
\text { wealth in the data }\end{array}$ \\
\hline Motor vehicle tax & $\begin{array}{l}\text { Taken from } \\
\text { the data }\end{array}$ & $\begin{array}{l}\text { Taken from } \\
\text { the data }\end{array}$ & $\begin{array}{l}\text { No information on vehicle values } \\
\text { in the data }\end{array}$ \\
\hline
\end{tabular}

Notes: Market income is the sum of employment and self-employment income, bonuses, in-kind income, auto-consumption from self-employment activities, capital and property income, inter-household payments, private transfers, minus alimony payments. Imputed rent is not included as part of market income.

Source: Authors' compilation.

ECUAMOD and COLMOD to those of external benchmarks (see detailed discussions in Jara et al. 2017 and Rodriguez 2017). We observe that simulations somewhat underestimate the number and aggregate amount of SIC payments. For Ecuador, the underestimation is important for self-employment SICs, which might be related to difficulties of capturing self-employment income in the survey. As for income tax, we also underestimate the number of payers and aggregate annual amounts in Ecuador and Colombia, even under the 
assumption of zero evasion. Yet, importantly for distributional analyzes, Cuesta and Jara (2017) show that the distribution of income tax payers by amount of income tax obtained using ECUAMOD simulations capture quite well the distribution of income tax payers according to administrative data. Regarding benefits, ECUAMOD captures very well the number of recipients of the HDT but underestimates the annual expenditure in this benefit. This might be related to additional costs added to the expenditures in HDT payments in external statistics. On the other hand, the Joaquín Gallegos Lara is underestimated, which is due to the fact that the survey does not properly capture recipients of this benefit, as eligibility in our simulation is based on receipt in the data. For Colombia, the number of recipients of Familias en acción and Colombia Mayor is somewhat underestimated; however, the annual aggregate amounts of Colombia Mayor match external statistics well.

Tables A3 and A4 in the Online appendix present a comparison of poverty and inequality results from ECUAMOD and COLMOD, with those obtained directly from ENIGHUR and ECV, and with respect to official statistics. Poverty and inequality estimated with ECUAMOD and COLMOD only slightly underestimate those obtained from ENIGHUR and ECV data. The underestimation is more important with respect to official statistics. The reason behind the discrepancies is that official statistics are based on different surveys than those used in our models. In particular, for Ecuador, the National Survey of Employment, Underemployment and Unemployment (ENEMDU) is used to produce official estimates of income poverty and inequality. The discrepancy is mainly driven by the fact that ENIGHUR, on which ECUAMOD input data are based, contains much more detailed income information than ENEMDU (Jara et al. 2017).

\subsection{Decomposition}

This section draws on the methodology described by Bargain (2012) applied to the context of swapping tax-benefit systems between two countries. We first introduce some notation and terminology. By household 'gross income' or 'market income', we mean the total amount of labor income, capital income and private pensions, before taxes and benefits (the treatment of replacement incomes and contributory benefits is detailed below). 'Disposable income' is the household income that remains after payment of taxes/social contributions and receipt of all cash transfers, as widely used to measure poverty and inequality. Let matrix $y_{c}$ describe the population contained in the data of country $c$, i.e., each row contains all the information about a given household (various market income sources and sociodemographic characteristics). Let $d_{c}$ denote the 'tax-benefit function' transforming, for each household, market/gross incomes and household characteristics into a certain level of disposable income. Tax-benefit calculations depend also on a set of monetary parameters $p_{c}$ (maximum benefit amounts, threshold level of tax brackets, etc.). Household disposable income is represented by $d_{i}\left(p_{j}, y_{k}\right)$ for a hypothetical scenario including the population of country $k$, the tax-benefit parameters of country $j$ and the tax-benefit structure of country $i$. A welfare index, such as a measure of inequality or poverty, can be calculated on the basis of the distribution of disposable income and is denoted $I\left[d_{c}\left(p_{c}, y_{c}\right)\right]$

Policy differences between two countries combine differences in policy structure $d$ and in parameters $p$ (for instance, they may have the same income tax system but different tax band levels). As the policies of a given country are specific to its income distribution, and notably to the overall income level, we also consider the possibility of nominally adjusting incomes by an uprating factor $\alpha$ That is, differences in income levels between country 1 and country 2 can be adjusted by using the indexation factor $\alpha$ defined as the mean income of country 2 divided by mean income of country 1 . As a result, $\alpha y_{1}$ retains the structural 
characteristics of country 1 (demographics, market income distribution, etc.) but adopt the mean income level prevailing in country 2 . Hence, we can represent counterfactual distributions as $d_{2}\left(p_{2}, \alpha y_{1}\right)$, the distribution of disposable incomes obtained by applying tax-benefit rules and parameters of country 2 on nominally adjusted data of country 1 . This backdrop is used in the decompositions that follow and so is the symmetrical situation where we evaluate the distribution obtained with the policy system of country 1 applied to the population of country 2 . Yet the latter is written $d_{1}\left(\alpha p_{1} y_{2}\right)$, whereby tax-benefit parameters are nominally adjusted to country 2's levels using the same factor $\alpha$.

The total difference $\Delta$ in the welfare indicator $I$ between country 1 and country 2 can be represented by:

$$
\Delta=I\left[d_{2}\left(p_{2}, y_{2}\right)\right]-I\left[d_{1}\left(p_{1}, y_{1}\right)\right]
$$

The difference in the distribution of disposable income, as summarized by index $I$, can be decomposed into the contribution of the change in the tax-benefit rules ('policy effect') and the contribution of changes in the underlying gross income distribution (or any other effects not directly linked to policy changes). The former effect corresponds to a shift from $d_{1}\left(p_{1},.\right)$ to $d_{2}\left(p_{2},.\right)$ while the latter corresponds to the move from data of country 1 to data of country 2 .

Two alternative decompositions can then be represented. The first type (decomposition I) consists of a shift from country 1 data to country 2 data conditional on the policy rules of country 1 , followed by a move from policy of country 1 to policy of country 2 on country 2 data. Formally, this can be represented as:

$$
\begin{aligned}
\Delta= & \left\{I\left[d_{2}\left(p_{2}, y_{2}\right)\right]-I\left[d_{1}\left(\alpha p_{1}, y_{2}\right)\right]\right\} \text { (policy differences/gap) } \\
& +\left\{I\left[d_{1}\left(\alpha p_{1}, y_{2}\right)\right]-I\left[d_{1}\left(\alpha p_{1}, \alpha y_{1}\right)\right]\right\} \text { (other differences) } \\
& +\left\{I\left[d_{1}\left(\alpha p_{1}, \alpha y_{1}\right)\right]-I\left[d_{1}\left(p_{1}, y_{1}\right)\right]\right\} \text { (income differences). }
\end{aligned}
$$

The second type of decomposition (decomposition II) involves a change in policy (from 1 to 2 ) evaluated on the basis of (nominally adjusted) country 1 data, followed by a change in underlying data (from 1 to 2 ) conditional on the policy of country 2.

$$
\begin{aligned}
\Delta= & \left\{I\left[d_{2}\left(p_{2}, y_{2}\right)\right]-I\left[d_{1}\left(p_{2}, \alpha y_{1}\right)\right]\right\}(\text { other differences }) \\
& +\left\{I\left[d_{2}\left(p_{2}, \alpha y_{1}\right)\right]-I\left[d_{1}\left(\alpha p_{1}, \alpha y_{1}\right)\right]\right\} \text { (policy differences/gap) } \\
& +\left\{I\left[d_{1}\left(\alpha p_{1}, \alpha y_{1}\right)\right]-I\left[d_{1}\left(p_{1}, y_{1}\right)\right]\right\} \text { (income differences). }
\end{aligned}
$$

In the case the tax-benefit function $d_{c}\left(p_{c}, y_{c}\right)$ is linearly homogenous in $p_{c}$ and $y_{c}$, a simultaneous change in nominal levels of both incomes and parameters - be it from a shift of currency or an application of factor $\alpha$ - should not affect the relative location of households in the distribution of disposable income. Hence, the third component ("income differences") of equations (I) and (II) should disappear.

As explained by Shorrocks (2013), the Shapley value procedure extracts the marginal effect on a poverty/inequality statistic I of eliminating each of the contributory factors in sequence, and then assigns to each factor the average of its marginal contributions in all possible elimination sequences. In the present case, if the homogeneity property is verified, the 'policy gap' and the 'other gaps' under the Shapley decomposition are thus obtained by averaging the contributions from the two decompositions set out above. Hence, it is possible to quantify the relative weight of the policy gap in explaining country differences in poverty/inequality. It is also possible to examine the sensitivity of the results to the choice of the decomposition (I, II or or the averaged Shorrocks-Shapley decomposition). 


\section{Empirical results}

This section presents the results of our comparative assessment of the redistributive role of tax-benefit systems in Ecuador and Colombia for the policy year 2014. We first discuss the relative size of tax-benefit instruments in each country. Then, we present the main results of our decomposition exercise to disentangle the role of tax-benefit policies in explaining differences in income poverty and inequality between countries. Finally, we discuss the contribution of particular policy instruments in reducing poverty and inequality.

\subsection{Relative size of tax-benefit components}

The relative size of four tax-benefit instruments by household disposable income decile is presented in Fig. 1 for Ecuador and Colombia. The average size of each component is measured as a percentage of average household disposable income per income decile. Taxes and social insurance contributions are shown as negative values as they represent deductions from disposable income.

Our results show the extent to which social assistance succeeds in targeting groups at the lower end of the income distribution in both countries. Social assistance benefits represent on average $17 \%$ of household disposable income for individuals in the bottom decile in Ecuador and 26\% in Colombia. The proportion of household disposable income represented by social assistance decreases with income levels. On the contrary, contributory public pensions are regressive with respect to disposable income in both countries, and particularly so in Colombia. The relative size of public pensions increases with household disposable income and represents around $14 \%$ of household disposable income for the top decile in Colombia, and around 5\% in Ecuador. This pattern might be related to the fact that many low income individuals are not affiliated to social security and would therefore not be entitled to public pensions. As previously mentioned, public pensions are not simulated in our models due to lack of information about contribution records to social security in the data. Differences in the design of pensions between Ecuador and Colombia would not be captured as part of the 'policy effect' in our decomposition analysis but would enter as part of the differences in market income distribution.

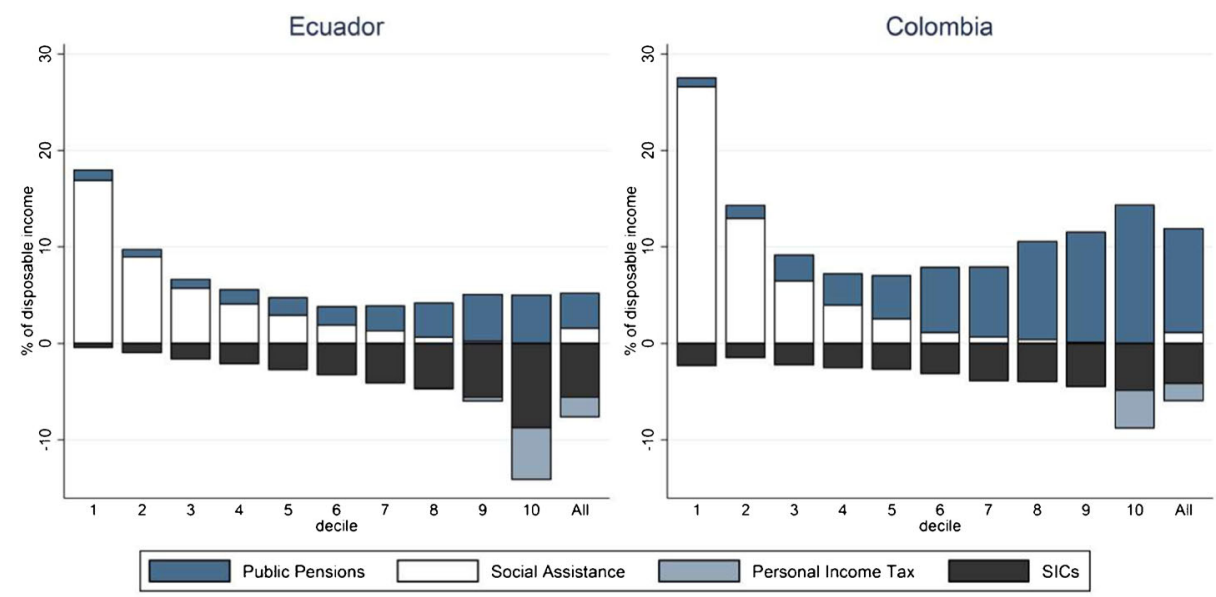

Fig. 1 Tax-benefit components as a share of household disposable income (2014) Source: ECUAMOD version 1.0 and COLMOD version 1.0 
Table 3 Effect of tax-benefit systems on income inequality and poverty (2014)

\begin{tabular}{|c|c|c|c|c|c|c|}
\hline & \multicolumn{3}{|c|}{$\begin{array}{l}\text { Inequality } \\
\text { (Gini coefficient \%) }\end{array}$} & \multicolumn{3}{|l|}{$\begin{array}{l}\text { Poverty } \\
\text { (FGT0 \%) }\end{array}$} \\
\hline & $\begin{array}{l}\text { Disposable } \\
\text { income }\end{array}$ & $\begin{array}{l}\text { Market } \\
\text { income }\end{array}$ & Difference & $\begin{array}{l}\text { Disposable } \\
\text { income }\end{array}$ & $\begin{array}{l}\text { Market } \\
\text { income }\end{array}$ & Difference \\
\hline Ecuador & 46.2 & 50.1 & -3.9 & 18.0 & 21.6 & -3.6 \\
\hline Colombia & 56.4 & 59.2 & -2.8 & 36.3 & 39.8 & -3.5 \\
\hline
\end{tabular}

Source: ECUAMOD version 1.0 and COLMOD version 1.0

Social insurance contributions are clearly progressive with respect to disposable income in Ecuador and represent around 8.8\% for the top income decile. In Colombia, SICs increase with disposable income but at a lower rate, and the presence of SIC payments in the bottom decile group is explained by the existence of a floor on SIC payments. As mentioned in the previous section, the data used in our analysis allows us to identify individuals who are affiliated to social security. SIC payments are simulated only for those affiliated to social security in Ecuador and Colombia under the baseline and counterfactual scenarios presented in the next section. In both countries, personal income tax plays a minor role and is noticeable only for the top income decile group, representing around 5\% of disposable income in Ecuador and 4\% in Colombia. This minor role is related to the presence of deductions from personal expenditures, applied to taxable income. As previously mentioned, personal income tax is simulated under the assumption of zero evasion in our analysis because of the difficulties of accounting for some sort of non-compliance in a comparable way for both countries. As we observe, even under the assumption of zero evasion, income tax plays a minor role affecting only the top decile of the income distribution.

The effect of the tax-benefit system on income inequality and poverty in Ecuador and Colombia in 2014 is presented in Table 3. The table compares results for the Gini coefficient and poverty headcount of household disposable income and household market income per capita. ${ }^{19}$ Absolute poverty is measured using a poverty line of USD 4.00 PPP per day, as for previous studies for Latin American countries. Our results are in line with previous findings in the literature. First, market income inequality and poverty are much higher in Colombia than in Ecuador, with the Gini coefficient for market income equal to 59.2 in Colombia compared to 50.1 in Ecuador, and market income poverty equal to $39.8 \%$ in Colombia and $21.6 \%$ in Ecuador. Second, the redistributive effect of the tax-benefit system in Ecuador is larger than in Colombia. Taxes and benefits reduce the Gini coefficient by 3.9 points in Ecuador compared to 2.7 points in Colombia. Finally, the tax-benefit system in Ecuador and Colombia have a similar effect on absolute poverty, with poverty falling by 3.6 points in Ecuador and 3.5 points in Colombia, when disposable income is compared to market income. The next section provides the results of our decomposition analysis in order to quantify the contribution of tax-benefit policies to differences in income inequality and poverty between countries.

\footnotetext{
${ }^{19}$ Most Latin American countries use household income per capita, i.e. household income divided by the number of persons in the household, for the measurement of income inequality and poverty.
} 


\subsection{Decomposition results}

The results of our decomposition analysis are presented in Table 4, which shows the different counterfactuals used in the decomposition, the overall difference in inequality/poverty between Ecuador and Colombia, the homogeneity check, and the results for decompositions I, II and the averaged Shapley decomposition. We present a series of inequality and poverty indicators to analyze in detail and for different population subgroups (e.g. children and the elderly) the effect of swapping tax-benefit systems between countries. These income distribution measures are again based on household disposable income per capita while absolute poverty is measured using a poverty line of USD 4.00 PPP per day.

Decomposition components First, we compare the baseline scenarios for Ecuador and Colombia which are reported in the columns indexed (0) and (4), respectively. These include results of Table 3 for the Gini and the FGT0. In particular, the Gini is much lower in Ecuador, i.e. $46.2 \%$ against $56.4 \%$ in Colombia, making up for a difference of 10.2 points as indicated in the 'Total difference' column. Additional inequality indicators, such as the Atkinson index and the P90/P10, confirm these results. Not only the overall poverty headcount (FGT0) is higher in Colombia, this is also the case for families with children and the elderly, as well as in terms of poverty gap (FGT1) and poverty severity (FGT2).

We can check whether the homogeneity property is respected. The column named 'Homogeneity check' shows the difference between the baseline scenario for Ecuador in column (0) and a counterfactual scenario in column (1), where the Ecuadorean tax-benefit system is applied to Ecuadorean data with all monetary variables adjusted by differences in incomes between Ecuador and Colombia (captured by the parameter $\alpha$ in the equations above). The difference between the baseline scenario (0) and the counterfactual (1) is equal to zero for all measures in the table, confirming that homogeneity holds. As previously mentioned, if the homogeneity property is respected, as it is the case here, then the third term of decompositions (I) and (II) disappears.

Two additional counterfactual scenarios are presented in Table 4 to perform our decomposition. On the one hand, column (2) represents a scenario where the Ecuadorean tax-benefit system has been applied to Colombian data. For instance, the Gini coefficient for the Colombian population if the Ecuadorean tax-benefit system was in place would be equal to $54.7 \%$, which is lower than the baseline Gini coefficient for Colombia of $56.4 \%$ (column 4). On the other hand, column (3) represents a counterfactual scenario whereby the Colombian tax-benefit system has been applied to the Ecuadorean population, leading to a Gini coefficient of $48.2 \%$ in Ecuador, slightly larger than the actual one (46.2\%, as reported in column 0).

Decomposition results The last 6 columns present the decomposition results under decomposition (I), (II) and the averaged Shorrocks-Shapley decomposition. As explained, the total effect is decomposed between the tax-benefit policy effect and the 'other effect'. The latter includes all the factors not related to tax-benefit policies as simulated in our exercises, and notably differences in market income inequality and in demographics. The policy effect is calculated as moving from the Colombian to the Ecuadorian system when using either Colombian data (decomposition I) or Ecuadorian data (decomposition II). Both decompositions give similar orders of magnitude for most inequality and poverty indices, which show that the results are not too sensitive to the underlying population used for the decomposition. The Shorrocks-Shapley average values give a useful summary in this context. 


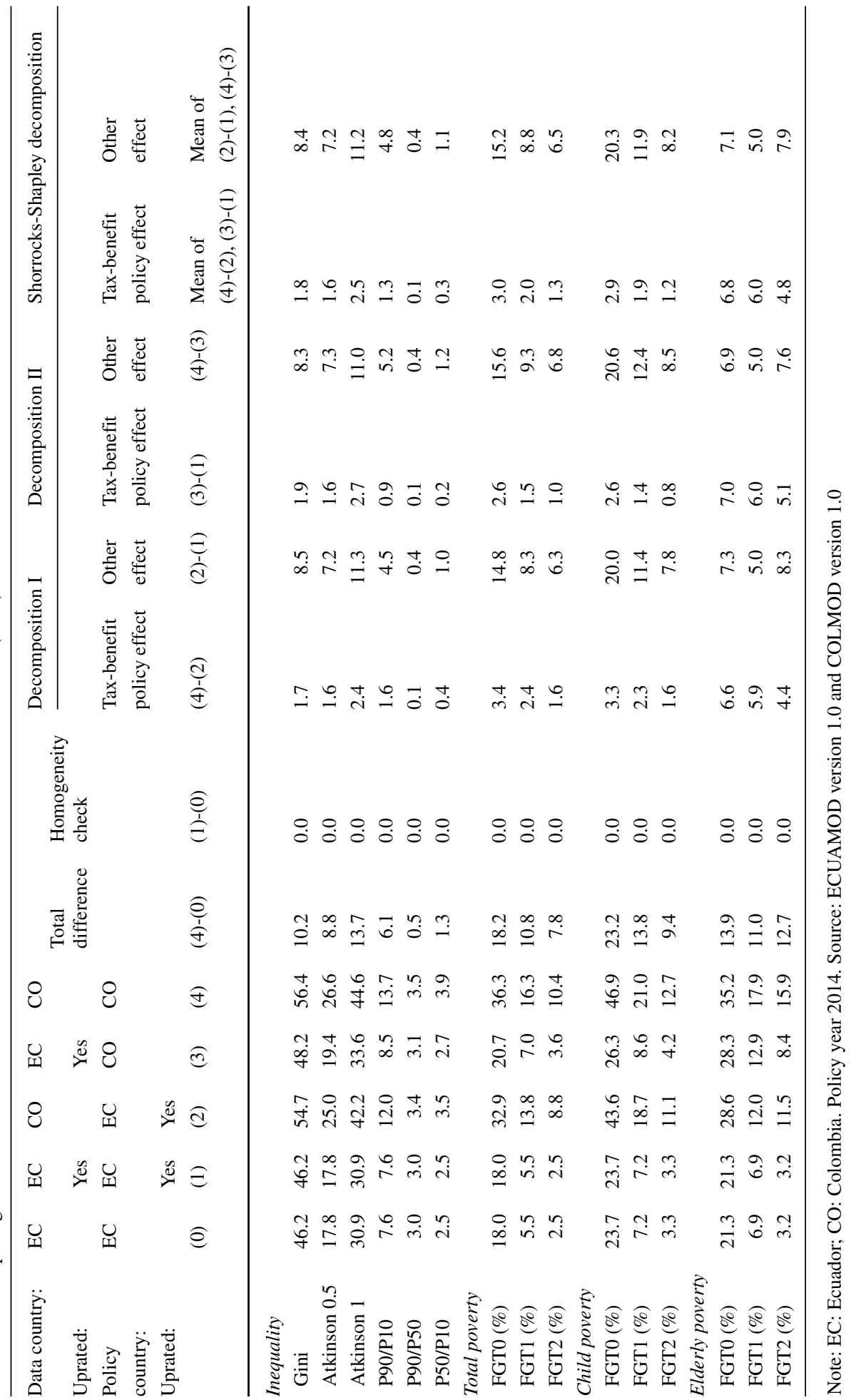


Bear in mind that differences in non-simulated tax-benefit components, such as contributory pensions, are captured as part of the 'other effect': the policy effect only captures differences in social assistance benefits, personal income tax and social insurance contributions between Ecuador and Colombia.

As expected, both decomposition results (I) and (II) show that most of the difference in inequality and poverty between Ecuador and Colombia is driven by the 'other effect'. Nonetheless, we find that tax-benefit policy differences are not negligible. According to the averaged Shorrocks-Shapley, the policy effect explains between $17.6 \%$ and $23.1 \%$ of the income inequality difference between countries depending on the inequality measure at use. For instance, a difference of 1.8 point is observed for the Gini, meaning that the difference in inequality between the countries, as measured by the Gini, would fall by $17.6 \%$ if the Ecuadorian system was used in Colombia.

The policy effect also explains up to $16.4 \%$ of the difference in poverty headcount (3 percentage points) and $18.5 \%$ of the difference in poverty intensity ( 2 points). This contribution is similar in the case of child poverty ( 2.9 and 1.9 points respectively), yet a little smaller in relative terms ( $12.5 \%$ and $13.7 \%$ respectively). The contribution of the policy effect is considerably larger for elderly poverty, both in absolute terms (6.8 and 6 points respectively) and relative terms (48.9\% and 54.5\% respectively). That is, around half of the country difference in elderly poverty is explained by the greater redistribution operated in Ecuador in favor of this group. It is worth reemphasizing that contributory pensions are not simulated in our models, therefore, the effect of the Ecuadorean tax-benefit system on Colombian elderly poverty can most likely be attributed to the effect of the Human Development Transfer, which would offer a more generous social assistance benefit for the elderly not affiliated to social security in Colombia. The contribution of specific tax-benefit components to income inequality and poverty for our baseline and counterfactual scenarios is discussed in detail in the next section.

\subsection{Marginal contributions of tax-benefit components}

The effect of particular tax-benefit instruments (social assistance, income tax and SICs) on income inequality and poverty is presented for each of our counterfactual scenarios in Table 5. For social assistance, taxes and SICs respectively, we calculate their marginal contribution to decreasing disposable income inequality/poverty (compared to market income inequality) as follows: we take the difference between inequality/poverty of disposable income and inequality/poverty of income before social assistance is added or before income/SICs are withdrawn. For instance, in the first panel showing the marginal contribution to Gini coefficient reduction, we can read in the following in the 'DPI minus social assistance' row: in our baseline scenario for Ecuador (column 0), social assistance benefits decrease income inequality by 1.4 points, which is obtained from the difference between the Gini coefficient of disposable income (46.2) and the Gini coefficient of disposable income excluding social assistance benefits (47.6). Social assistance also contributes the most to inequality reduction in the Colombian baseline (column 4) with a reduction of 1.1 points in the Gini coefficient. Our swapping exercise shows that applied to the Colombian population, the Ecuadorean social assistance benefit would achieve the largest reduction in inequality (column 3), with a difference of 1.8 points in the Gini coefficient. In contrast, under the counterfactual where the Colombian tax-benefit system is applied to Ecuador (column 4), social assistance would decrease inequality by only 0.8 points.

The contribution of personal income tax and SICs to inequality reduction is also larger in Ecuador (column 0) compared to Colombia (column 4). Personal income tax reduces 
Table 5 Effect of tax-benefit components on poverty and inequality

\begin{tabular}{|c|c|c|c|c|c|}
\hline Data country: & $\mathrm{EC}$ & $\mathrm{EC}$ & $\mathrm{CO}$ & $\mathrm{EC}$ & $\mathrm{CO}$ \\
\hline Uprated: & & Yes & & Yes & \\
\hline Policy country: & $\mathrm{EC}$ & $\mathrm{EC}$ & $\mathrm{EC}$ & $\mathrm{CO}$ & $\mathrm{CO}$ \\
\hline \multirow[t]{2}{*}{ Uprated: } & & Yes & Yes & & \\
\hline & $(0)$ & (1) & (2) & (3) & (4) \\
\hline \multicolumn{6}{|l|}{$\Delta$ Gini coefficient } \\
\hline DPI minus social assistance & -1.4 & -1.4 & -1.8 & -0.8 & -1.1 \\
\hline DPI plus income tax & -1.1 & -1.1 & -1.3 & -0.9 & -0.7 \\
\hline DPI plus SICs & -1.3 & -1.3 & -1.1 & 0.0 & -0.4 \\
\hline \multicolumn{6}{|l|}{$\Delta$ Poverty headcount } \\
\hline DPI minus social assistance & -2.6 & -2.6 & -2.4 & -1.3 & -1.1 \\
\hline DPI plus income tax & 0.1 & 0.1 & 0.2 & 0.0 & 0.2 \\
\hline DPI plus SICs & 0.3 & 0.3 & 0.7 & 0.4 & 0.8 \\
\hline \multicolumn{6}{|l|}{$\Delta$ Child poverty headcount } \\
\hline DPI minus social assistance & -2.6 & -2.6 & -2.3 & -1.5 & -1.2 \\
\hline DPI plus income tax & 0.1 & 0.1 & 0.2 & 0.0 & 0.2 \\
\hline DPI plus SICs & 0.5 & 0.5 & 0.9 & 0.3 & 0.9 \\
\hline \multicolumn{6}{|l|}{$\Delta$ Elderly poverty headcount } \\
\hline DPI minus social assistance & -8.2 & -8.2 & -7.3 & -2.9 & -2.9 \\
\hline DPI plus income tax & 0.2 & 0.2 & 0.4 & 0.2 & 0.3 \\
\hline DPI plus SICs & 0.1 & 0.1 & 0.5 & 0.5 & 0.7 \\
\hline
\end{tabular}

Note: EC: Ecuador; CO: Colombia. DPI= Disposable Income. Policy year 2014

Source: ECUAMOD version 1.0 and COLMOD version 1.0

income inequality by 1.1 points in the Ecuadorian baseline, whereas it account for 0.7 points reduction in the Colombian baseline. Under the counterfactual case of the Ecuadorean (Colombian) system applied to the Colombian (Ecuadorean) population, the marginal contribution of income tax increases (decreases) to 1.3 (0.9) points. Finally, SICs have only a minor effect on inequality in Colombia (column 4) and the same holds when the Colombian system is applied to Ecuador (column 3). This could be linked to the existence of floor payments in SICs under the Colombian system, which affects individuals at the lower end of the income distribution as observed in Fig. 1 above.

In terms of poverty reduction, social assistance benefits play an essential role. Income tax and SICs tend to increase absolute poverty (positive sign of their marginal contributions), as they are paid by everyone including the poor - this is especially the case of SICs in Colombia, which is consistent with Fig. 1. Their effect remains small nevertheless. The marginal contribution of social assistance reduces overall poverty by 2.6 points in the Ecuadorean baseline (column 0) compared to 1.1 points in Colombia (column 4). These differences are reflected in the contribution of social assistance under our counterfactual swapping scenarios. The marginal contribution of social assistance doubles (reduces by half) under the counterfactual where the Ecuadorean (Colombian) system is applied to Colombia (Ecuador). In terms of child poverty, the marginal effect of tax-benefit components on is very similar in magnitude to that of the whole population. 
The major role played by social assistance benefits in Ecuador is observed in terms of their contribution to poverty reduction among the elderly. Social assistance benefits in Ecuador (column 0) reduce poverty in this group by 8.2 points, whereas their marginal contribution is 2.9 points in Colombia (column 4). Our decomposition results in the previous section showed that the poverty headcount among the elderly would drop by 6.6 points in Colombia if the Ecuadorean tax-benefit system would be applied to its population. As previously mentioned, such effect could be attributed to the more generous social assistance benefits in Ecuador, given that contributory pensions are not simulated in our models. Table 5 confirms these results. In the case the Ecuadorean system would be applied to Colombia (column 2), the marginal contribution of social assistance benefits to elderly poverty reduction would increase substantially from 2.9 to 7.3 points, because of the more generous benefit amount of the Human Development Transfer from Ecuador for old-age individuals not covered by social security.

Our characterization may be sensitive to the path of the decomposition. To check this, we alternatively assess the effect of tax-benefit components on income inequality/poverty when starting from market income (i.e. when adding social assistance to or withdrawing taxes/SICs from market income). Table A5 in the Online appendix presents the results of this alternative calculation and shows that the results are broadly consistent. Social assistance benefits play the biggest role in inequality and poverty reduction and particularly so under the Ecuadorean baseline and in the counterfactual where the Ecuadorean system would be applied to the Colombian population.

\section{Conclusions}

The decreasing trend in income inequality observed over the recent decades in Latin American countries has inspired numerous studies on the factors behind such improvement. Lower wage inequality is the main driver behind the decline in household income inequality. However, as pointed by De la Torre et al. (2017) "the contribution of nonlabor income cannot be disregarded as minor". In fact, many countries in the region have made important progress in reforming their tax-benefit systems to achieve larger redistribution, through more progressive income taxation and higher cash transfers to vulnerable populations.

The present paper takes advantage of the recent development of harmonized tax-benefit models for Ecuador and Colombia to provide one of the first comparative settings for microsimulation in Latin American countries, and contributes to the recent literature on the redistributive role of tax-benefit systems in Latin America in two main respects. First, we use detailed legislation rules and information from household surveys to simulate taxbenefit components that are not directly available in the household survey data and need to be calculated in order to assess their effect on poverty and inequality. Second, we propose a decomposition approach based on counterfactual scenarios obtained by swapping tax-benefit systems between Ecuador and Colombia in order to quantify the relative effect of the tax-benefit policies in income inequality and poverty compared to all other effects, including differences in the distribution of market incomes between the two countries.

Our results point to a modest but non-negligible redistributive role of tax-benefit systems in Ecuador and Colombia, in line with previous studies. The Ecuadorean tax-benefit system is more redistributive, and if applied to the Colombian population, would decrease income inequality and poverty more than the Colombian system does. The poverty reducing effect of the Ecuadorean tax-benefit system would be the largest for the elderly in Colombia. Social assistance benefits in Ecuador play an important redistributive role and achieve a 
large reduction in income poverty. In particular, the reduction of poverty among the elderly under the counterfactual scenario where the Ecuadorean system is applied to the Colombian population is related to the Human Development Transfer from Ecuador, which provides a more generous social assistance benefit for the elderly not protected by social security.

From a policy perspective, our paper stresses the importance of developing harmonized microsimulation models for Latin American countries to learn from other countries in designing tax-benefit systems, and to promote further developments of socio-fiscal systems in countries in the region. Expanding the development of microsimulation models to other countries in the region would, for instance, allow us to quantify the extent to which countries with similar levels of market income inequality diverge in terms of redistribution. At the regional level, previous research has shown that the decline in income inequality has gone hand-in-hand with an increase in income tax revenue and public spending per capita. It would be interesting to analyze whether the drop in income inequality has been more marked in countries where social benefit and/or tax have progressed the most.

The role of indirect taxes and in-kind benefits was not considered in our analysis. The overall picture of our results should, however, not be affected if these components were included. On the one hand, a recent study by Rojas Báez (2017) shows that indirect taxes are fairly proportional with respect to disposable income in Ecuador but have a more regressive nature in Colombia. The Ecuadorean tax-benefit system would therefore be even more redistributive if applied to the Colombian population when VAT is taken into account. On the other hand, social spending in education and health are of broadly similar size in the two countries, representing around $8.7 \%$ of GDP in Ecuador and $9.5 \%$ in Colombia. Assessing the redistributive effect of in-kind benefits on income redistribution is, however, a very complex task as it requires estimating the monetary value of public services and assigning it to particular individuals in the data. The effect of in-kind benefits on income redistribution would necessarily be affected by the assumptions made about individuals benefiting from public services.

Several extensions or improvements could be considered for future research. For instance, our paper captures only the direct effect of swapping tax-benefit rules in the decomposition. Potential behavioral responses or general equilibrium effects of applying the tax-benefit system of another country could be considered in the future. For the purpose of this analysis, we also assumed zero evasion of personal income tax. As such, our results are interpreted as capturing the intended effect of personal income tax, which appeared to be very small. Potential reactions in terms of tax-evasion could also be considered when the system of one country is applied to the population of another. However, identifying the individuals most likely to evade taxes in a comparative setting is a challenging task. The above mentioned issues require careful consideration and represent promising subjects for future research.

Acknowledgments This work was supported by the Economic and Social Research Council (ESRC) through the Research Center on Micro-Social Change (MiSoC) at the University of Essex, grant number ES/L009153/1. The results presented here are based on ECUAMOD v1.0 and COLMOD v1.0. ECUAMOD is developed, maintained and managed by UNU-WIDER in collaboration with the EUROMOD team at ISER (University of Essex), SASPRI (Southern African Social Policy Research Institute) and local partners in selected developing countries (Ethiopia, Ghana, Mozambique, Tanzania, Zambia, Ecuador and Viet Nam) in the scope of the SOUTHMOD project. The local partner for ECUAMOD is Instituto de Altos Estudios Nacionales (IAEN). We are indebted to the many people who have contributed to the development of SOUTHMOD and ECUAMOD. The results and their interpretation presented in this publication are solely the authors' responsibility. 
Open Access This article is distributed under the terms of the Creative Commons Attribution 4.0 International License (http://creativecommons.org/licenses/by/4.0/), which permits unrestricted use, distribution, and reproduction in any medium, provided you give appropriate credit to the original author(s) and the source, provide a link to the Creative Commons license, and indicate if changes were made.

\section{References}

Abad, L.A., Lindert, P.H.: Fiscal redistribution in Latin America Since the Nineteenth Century. In: Bértola, L., Williamson, J. (eds.) Has Latin American Inequality Changed Direction? pp. 243-282. Springer, Cham (2017)

Alvaredo, F., Gasparini, L.: Recent trends in inequality and poverty in developing countries. In: Atkinson, A.B., Bourguignon, F. (eds.) Handbook of income distribution, vol. 2, pp. 697-805. Elsevier, Amsterdam (2015)

Atkinson, A.B., Bourguignon, F.: Tax-benefit models for developing countries: lessons from developed countries, Ecole Normale Superieure, DELTA Working Paper 90-15, Paris (1990)

Atkinson, A.B., Bourguignon, F., Chiappori, P.-A.: What do we learn about tax reform from international comparisons? France and Britain. Eur. Econ. Rev. 32(2-3), 343-352 (1988)

Bargain, O.: The distributional effects of tax-benefit policies under new labour: a decomposition approach. Oxf. Bullet. Econ. Stat. 74, 6 (2012)

Bargain, O., Callan, T.: Analysing the effects of tax-benefit reforms on income distribution: a decomposition approach. J. Econ. Inequal. 8(1), 1-21 (2010)

Barreix, A., Roca, J., y Villela, L.: La equidad fiscal en los países andinos, BID-Eurosocial (2006)

Bernal, N.: Los gastos públicos en pensiones en América Latina y sus proyecciones al año 2075: evidencia de Chile, Perú, Colombia y México. Apuntes: Revista de Ciencias Sociales, [S.1.], p. 79-128, ISSN 2223-175 (2016)

CEPAL: Una década de desarrollo social en América Latina 1990-1999, Naciones Unidas-CEPAL (LC/G.2212-P), Santiago de Chile. Note: CEPAL is the Economic Commission for Latin America and the Caribbean (Comisón Económica para Amércia Latina y el Caribe) (2004)

CEPAL-IEF: Los efectos de la política fiscal sobre la redistribución en América Latina y la Unión Europea. (Estudio no. 8). Serie Estados de la Cuestión. Available at: http://sia.eurosocial-ii.eu/files/docs/ 1412088027-Estudio8deffinal.pdf (2014)

Cord, L.J., Cabanillas, O.B., Lucchetti, L., Rodríguez-Castelán, C., Sousa, L.D., Valderrama, D.: Inequality stagnation in Latin America in the aftermath of the global financial crisis. Policy Research Working Paper 7146. World Bank, Washington (2014)

Cuesta, M., Jara, H.X.: Quién debe pagar impuestos? Un análisis de microsimulación para el impuesto a la renta de personas naturales en el Ecuador, mimeo (2017)

DANE: Cuentas Anuales de los Sectores Institucionales, Cuentas Económicas Integradas. Available at: http:// Dane.Gov.Co/Files/investigaciones/pib/anuales/ccrgbase2005/CEISerie20002015prov.xls (2017a)

DANE: Gastos del gobierno por finalidad. Available at: http://dane.gov.co/files/investigaciones/pib/anuales/ ccrgbase2005/Bolclasgastogob2016pre.pdf (2017b)

De Lathouwer, L.: A case study of unemployment scheme for Belgium and the Netherlands. In: Harding, A. (ed.) Microsimulation and Public Policy, Chapter 4, pp. 69-92. Elsevier, Amsterdam (1996)

De la Torre, A., Messina, J., Silva, J.: The inequality story in latin america and the caribbean: Searching for an explanation. In: Bértola, L., Williamson, J. (eds.) Has Latin American Inequality Changed Direction? pp. 317-338. Springer, Cham (2017)

OECD/ECLAC/CIAT/IDB: Revenue Statistics in Latin America and the Caribbean 2017. OECD Publishing, Paris (2017)

Goñi, E., Lopéz, J., Servén, L.: Fiscal distribution and income inequality in latin america. World Dev. 39(9), 1558-1569 (2011)

Immervoll, H., Levy, H., Nogueira, J.R., O’Donoghue, C., de Siqueira, R.B.: The Impact of Brazil's TaxBenefit System on Inequality and Poverty. In: Klasen, S., Nowak-Lehmann, F. (eds.) Poverty, Inequality, and Policy in Latin America. MIT Press, Cambridge (2009)

IESS: Informe de Labores - 2014. Instituto Ecuatoriano de Seguridad Social. Consejo Directivo. Representación del sector empleador. IESS (2014)

INEC: Reporte de Pobreza y Desigualdad - Diciembre 2016. INEC. Available at: http://www. ecuadorencifras.gob.ec/documentos/web-inec/POBREZA/2016/Diciembre2016/Reporte\%20pobreza \%20y\%20desigualdad-dic16.pdf (accessed June 2017) (2016) 
Jara, H.X., Varela, C., Cuesta, M., Amores, C.: SOUTHMOD Country Report Ecuador. ECUAMOD v1.0. 2011-2016. Helsinki, UNU-WIDER (2017)

Levy, H., Lietz, C., Sutherland, H.: Swapping policies: Alternative tax-benefit strategies to support children in Austria, Spain and the UK. J. Soc. Policy 36, 625-647 (2007b)

Llellena, P., Paul, F., Llerena Pinto, M.C., Saá Daza, R.C., Llerena Pinto, M.A.: Social Spending, Taxes and Income Redistribution in Ecuador, documento de trabajo del CEQ núm 28, Instituto CEQ. Tulane University/ FIDA / ICEFI, Washigton D. C. (2015)

López-Calva, L.F., Urzúa, C.M.: Sistemas de impuestos y prestaciones en América Latina. BUAP-IDRCITESM-PNUD, México D.F (2011)

Lustig, N., López-Calva, L., Ortiz-Juarez, E.: Declining inequality in Latin America in the 2000s: The cases of Argentina, Brazil, and Mexico. World Dev. 44, 129-141 (2013)

Lustig, N.: 'El impacto del sistema tributario y el gasto social en la distribución del ingreso y la pobreza en América Latina. Una aplicación del marco metodológico del Proyecto Compromiso con la Equidad (CEQ). El Trimestres Económico, vol. LXXXIV (3), núm. 335, 493-568 (2017)

OECD: Government at a glance: Latin America and the Caribbean 2017. OECD Publishing, Paris (2017)

Urzúa, C.M.: Fiscal inclusive development: Microsimulation Models for Latin America. IDRC- UNDP ITESM, México DF (2012)

Rodriguez, D.: COLMOD: The tax-benefit model for Colombia. Country Report, mimeo (2017)

Robles, M., Rubio, M.G., Stampini, M.: Have Cash Transfers Succeeded in Reaching the Poor in Latin America and the Caribbean?, Inter-American Development Bank (2015)

Rojas Baez, D.: Análisis de regresividad del IVA en el Ecuador, Notas de Reflexión, Política fiscal y tributaria, 40. Quito: Center for Fiscal Studies, SRI (2017)

Shorrocks, A.F.: Decomposition procedures for distributional analysis: A unified framework based on the shapley value. J. Econ. Inequal. 11(1), 99-126 (2013)

Salanauskaite, L., Verbist, G.: Is the neighbour's grass greener? Comparing family support in Lithuania and four other New Member States. J. Eur. Soc. Policy 23(3), 315-331 (2013)

Sutherland, H., Figari, F.: EUROMOD: the european union tax-benefit microsimulation model. Int. J. Microsimulation 6(1), 4-26 (2013) 